\title{
Traumatic spinal cord injury due to human tower accident in Catalonia
}

\author{
Agnes Witt ${ }^{1} \cdot$ Hatice Kumru ${ }^{2,3,4} \cdot$ Eloy Opisso ${ }^{2,3,4} \cdot$ Joan Vidal ${ }^{2,3,4}$
}

Received: 20 September 2018 / Revised: 18 November 2018 / Accepted: 19 November 2018

(C) International Spinal Cord Society 2018

\begin{abstract}
Study design Retrospective case series.

Objectives The aim of this paper was to review the cases of SCI associated with human towers in the neurorehabilitation hospital Guttmann in Barcelona, clarify the mechanisms of these accidents and classify the injuries.

Settings and methods Data and history were retrospectively reviewed to detect SCI patients injured from human tower accidents admitted at the Guttmann Institute, Barcelona, in the period 1965-2017, from patient histories and interviews with patients and their relatives.

Results In total, five men with SCI acquired from "human tower" accidents were admitted between 1988 and 2017. All of them were at the base of the tower. They were all injured at cervical level, with very severe injury (AIS-A in two, AIS-B in one, and AIS-C in two). Two died due to pneumonia associated to mechanical ventilation at 4 and 10 years post injury. Conclusion Human tower is a rare cause of traumatic tetraplegia in Catalonia. People forming the base of the tower are at greater risk for injury. Moreover, in our case series, all accidents causing SCI occurred when the human tower was greater than seven levels and had over three participants at each level.
\end{abstract}

\section{Introduction}

The incidence of traumatic spinal cord injury (SCI) is around 12.3 new cases in 1 million habitants per year in Catalonia [1]. Some trauma mechanisms inducing SCI are seen in very local areas such as accidents among the palm tree climbers in Nigeria [2]; surfer's myelopathy in areas where surfing is popular [3]; surfer's myelopathy without surfing after spinal hyperextension [4]; following climbing

These authors contributed equally: Agnes Witt, Hatice Kumru

Hatice Kumru

hkumru@guttmann.com

1 Department of Clinical Neurophysiology, Aarhus University Hospital, Aarhus, Denmark

2 Institut Guttmann, Institut Universitari de Neurorehabilitació adscrit a la UAB, 089M6 Badalona, Barcelona, Spain

3 Univ Autonoma de Barcelona, 08M93 Bellaterra (Cerdanyola del Vallès), Barcelona, Spain

4 Fundació Institut d'Investigació en Ciències de 1,a Salut Germans Trias i Pujol, Badalona, Barcelona, Spain trees to find firewood and fruit In Tanzania [5]; sleeping in the darkness on roofs without parapet and falling during the night in India [6]; or during Khaneh Takani, a special kind of house cleaning performing before the new year in Iran [7]. Here, we described five cases of traumatic SCI in Catalonia, Spain, because of the folkloric activity of "human towers" or "Castells" in Catalan, as a cause of traumatic spinal cord injury.

Human towers also known as a castells are a Catalan tradition which goes back to 18th century (Figs. 1 and 2). In 2010, they became part of the Intangible World Heritage by the UNESCO and can be seen all around Catalonia throughout the year. Human tower building is a long-held Catalan tradition and involves layers of people climbing on to each other's shoulders. The castells (Figs. 1 and 2) appear in different formations varying in height, width, and number of people at each level. However, the towers always consist of a base comprising several, sometime hundreds of people in one, two, or three levels, and on top of that the trunk of the tower is built with one to nine participants on each level. The tower is considered successful when the person on the top, typically a child, raises the hand and climbs down the tower on the opposite side as ascended. The highest towers completed are of ten levels. 
In this paper, we report five cases with SCI since 1988 following accidents of human towers and discuss how each accident occurred and what caused the injuries and classify the injuries.

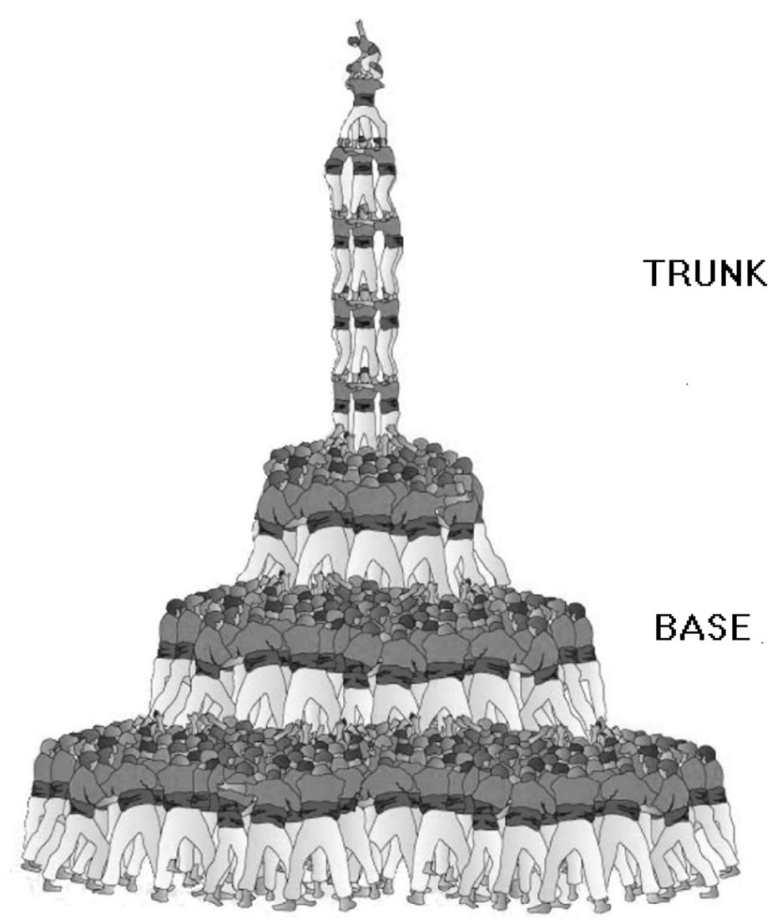

Fig. 1 Illustration of a human tower. This is an example of a tower of nine levels with three persons on each level (9 of 4). Adapted from Consorci per la Normalització Lingüística (CC-NC-SA)

\section{Methods}

Data and history were retrospectively reviewed to detect SCI patients injured from accidents of human towers admitted at the Guttmann Institute, Barcelona, in the period 1965-2017. Information was collected from patient history and interviewed with patients and their relatives. Inclusion criteria were: (1) spinal cord injury; (2) patient injured in a human tower. Exclusion criteria were traumatic brain injury (TBI).

The schematic and general information about human tower was given in Figs. 1 and 2. ASIA (American Spinal Cord Injury Association) Impairment Scale (AIS) and the International Standards for Neurological Classification of Spinal Cord Injury [8] were used to evaluate the severity and level of SCI.

\section{Results}

There were five SCI cases from 1965 until 2017 with first case reported in 1988. Clinical and demographical data of the patients are presented in the Table 1.

Case 1: A forty-nine-year-old man acquired an SCI 29 years ago. He was at the base of the human tower of eight levels, and four participants at each level (8/4 tower) (Fig. 1) when the human tower was destabilized and collapsed. At that moment, one of the participants felt straight down hitting the heel into the patient's neck causing a fracture of C5/C6 and a C5 AIS-C SCI.

Case 2: A forty-nine-year-old man was injured 21 years ago. He was part of the second base of what was about to be a nine-store human tower with five participants at each level (9/5 tower; Fig. 1) as the accident occurred. He tried to rest
Fig. 2 Close up of participants supporting their heads and necks on a castell. Standing close together they rest their arms on the back of the head or the neck of the person in front of them to protect their neck. Modified with permission from www.ccca.cat

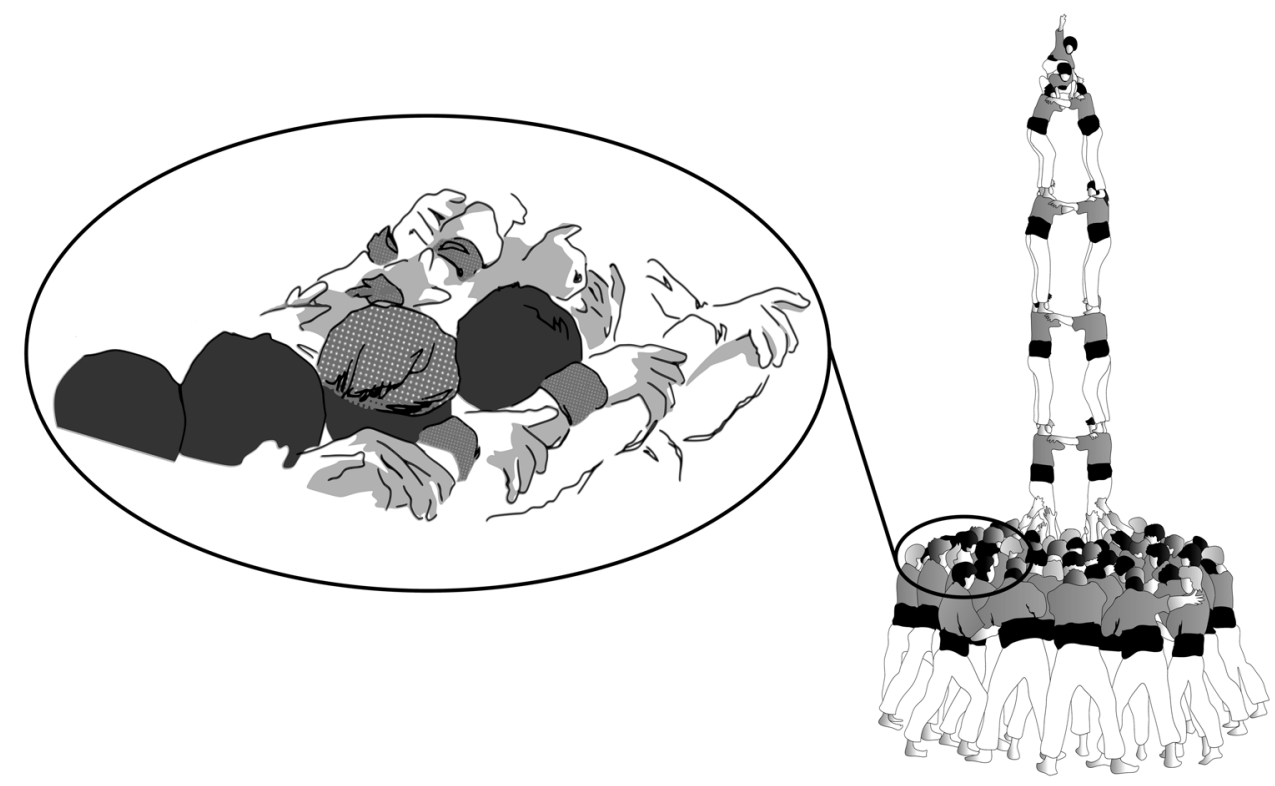


Table 1 Demographic and clinical data of patients with spinal cord injury (SCI)

\begin{tabular}{llllllll}
\hline Case & Sex & Age at SCI & Fracture of vertebrae & SCI level & AIS & Time since SCI & Actual situation \\
\hline 1 & M & 20 & C5/C6 & C5 & C & 29 years & Annual revision \\
2 & M & 28 & C5 & C5 & C & 21 years & Annual revision \\
3 & M & 57 & C4/C5 & C2 & A & 10 years & Died in 2012 \\
4 & M & 47 & C2/C3 & C2 & A & 4 years & Died in 2017 \\
5 & M & 62 & C6/C7 & C4 & B & 2 month & In-patient \\
\hline
\end{tabular}

AIS ASIA (American Spinal Cord Injury Association) Impairment Scale (AIS) his head on the back of the person in front of him, but the height difference was too much between them. At that moment, the human tower collapsed before it was completed because of instability, and a person fell down on the back of the head of the patient. As the falling person hit the head of the patient, it caused a hyperflexion of the neck resulting a fracture of C5 and a C5 AIS-C SCI.

Case 3: A 57-year-old man was at the base of an eight level four-person tower ( $8 / 4$ tower), right under the tower, when he was injured. To protect him from neck injuries the participant behind him had his arms on his back head (fig. 2 ), but when the $8 / 4$ tower tilted to the opposing site of the patient, all the participants at the base stepped back and removed the arms from their positions. Consequently, the neck of this patient was exposed, and he was hit by a falling participant causing a fracture of C4-C5. In the hospital, first he was treated with cervical traction; the neurological level of his SCI ascended to $\mathrm{C} 3$ requiring mechanical ventilation and surgery. Ultimately, he had a C2 AIS-A injury and was dependent on mechanical ventilation during rest of his life. He died 10 years post injury from pneumonia and pulmonary complications related to mechanical ventilation and SCI.

Case 4: A fifty-one year-old man was injured at the age of 47 . He was at the base of a tower of eight levels with five participants on each level (8/5 tower). The tower collapsed and the patient, who was a father of one of the children at the top of the tower, looked up to see what happened with her. At that moment, a person fell down on his head causing a hyperextension of the neck and thereby a fracture of $\mathrm{C} 2 /$ C3 and a C2 AIS-A SCI. He died 4 years post injury due to pneumonia and pulmonary complications related to mechanical ventilation and SCI.

Case 5: A sixty-two-year-old man was injured when he was at the center of the base of a nine levels of tower with four participants at each level (9/4 tower). When the tower collapsed the weight on the shoulders of base became uneven and the burden became too heavy for the 62-yearold man who incurred a fracture at C6-C7and a C4 AIS-B SCI. He is currently two months post injury.

\section{Discussion}

These case reports demonstrate: (1) human tower is cause of traumatic SCI and that is unique to Catalonia; (2) it is not a frequent cause of traumatic SCI: (3) SCI can occur in participants who are a part of the base of the human tower: (4) in all cases described the level of SCI was cervical level.

SCI occurs in participants who are a part of the base of the human tower: The base typically consists of stocky men ready to carry the burden of the tower. There are several guidelines stating how these men must stand to prevent any accidents and injuries. Standing close together they rest the arms on the back head or the neck of the person in front to protect their neck (Fig. 2). The head is placed on the back of the person in front to prevent any flexion of the neck in case someone falls down on them. In the four cases, it seems that for different reasons the neck was exposed or extended, which made the participants more vulnerable for cervical lesions. Only one of the participants extended the neck to look up (case 4), which is against the guidelines of human tower. In the remaining cases, it seemed more coincidental that the accidents had such tragic consequences.

The risk of an accident during a castell is significant. Thus to minimize the consequences of the accident, the community of "human towers" has developed a special public health guidance for the security of good practice [9]. Currently, it is mandatory for the children who climb to the top of the tower to wear helmets, and several circumstances have been changed to make the tradition of human towers as safe as possible [9].

Acknowledgements We want to thank to the patients and their families for their participation and for the given additional information. We want also to thank the "Coordinadora de Colles de Castellers de Catalunya" (the Human Tower Teams Coordinating Body) for facilitating for us the material for the figures of the paper.

\section{Compliance with ethical standards}

Conflict of interest The authors declare that they have no conflict of interest. 


\section{References}

1. Lesiones medulares traumáticas y traumatismos craneoencefálicos en España, 2000-2008 Sanidad 2011 /Ministerio de Sanidad, Política Social e Igualdad.

2. Okonkwo CA. Spinal cord injuries in Enugu, Nigeria-preventable accidents. Paraplegia. 1988;26:12-8.

3. Chang CW, Donovan DJ, Liem LK, O'Phelan KH, Green DM, Bassin S, et al. Surfers' myelopathy: a case series of 19 novice surfers with nontraumatic myelopathy. Neurology. 2012;79:2171-6.

4. Albuja AC, Qaiser S, Lightner DD, Raslau FD, Zafar MS, Bernard PA, et al. Surfer's myelopathy without surfing: a report of two pediatric patients. Spinal Cord Ser Cases. 2017;3:17008.
5. Moshi H, Sundelin G, Sahlen KG, Sorlin A. Traumatic spinal cord injury in the north-east Tanzania - describing incidence, etiology and clinical outcomes retrospectively. Glob Health Action. 2017;10:1355604.

6. Verma V, Singh A, Singh GK, Kumar S, Sharma V, Kumar A, et al. Epidemiology of trauma victims admitted to a level 2 trauma center of North India. Int J Crit Illn Inj Sci. 2017;7:107-12.

7. Mahdian M. Fall injuries: an important preventable cause of trauma. Arch Trauma Res. 2013;2:101-2.

8. Kirshblum SC, Burns SP, Biering-Sorensen F, Donovan W, Graves $\mathrm{DE}$, Jha $\mathrm{A}$, et al. International standards for neurological classification of spinal cord injury (revised 2011). J Spinal Cord Med. 2011;34:535-46.

9. Fem Pinya: http://www.cccc.cat/que-fem/Prevenciolesions/FemPinya 